INTERNATIONAL JOURNAL OF RESEARCHES IN BIOSCIENCES, AGRICULTURE AND TECHNOLOGY

(C) VISHWASHANTI MULTIPURPOSE SOCIETY (Global Peace Multipurpose Society) R. No. MH-659/13(N) www.vmsindia.org

\title{
EVALUATION OF FINE PARTICULATE MATTER POLLUTION
}

\author{
R. Deshmukh, D. C. Sindhimeshram and R. U. Khope \\ S.S.E.S Science College, Congress Nagar, Nagpur (M.S) India \\ reshaldeshmukh@rediffmail.com
}

\begin{abstract}
The interactions of fine and ultrafine particles with chemicals play a dominant role in determining the mobility and availability of pollutants in the environment. Fine particles in sediments can sequester chemicals from the water column, and release volatile and semi-volatile organic compounds to the gas phase upon exposure to air. Ultrafine particles which are photo reactive can degrade these vapor-phase contaminants, and may transform the molecules into species which are more toxic or hazardous than the parent. As the widespread, commercial use of ultrafine particles becomes more common, understanding the chemo dynamics of these particles and their interactions with chemicals in the environment becomes paramount.
\end{abstract}

Keywords: Particulate size, health problems, regulations

\section{Introduction:}

Some particulates occur naturally, originating from volcanoes, dust storms, forest and grassland fires, living vegetation, and sea spray. Human activities, such as the burning of fossil fuels in vehicles, power plants and various industrial processes also generate significant amounts of particulates. Coal combustion in developing countries is the primary method for heating homes and supplying energy. Because salt spray over the oceans is the overwhelmingly most common form of particulate in the atmosphere, anthropogenic aerosols those made by human activities currently account for about 10 percent of the total mass of aerosols in our atmosphere. The composition of aerosols and particles depends on their source. Windblown mineral dust tends to be made of mineral oxides and other material blown from the Earth's crust; this particulate is lightabsorbing. Sea salt is considered the secondlargest contributor in the global aerosol budget, and consists mainly of sodium chloride originated from sea spray; other constituents of atmospheric sea salt reflect the composition of sea water, and thus include magnesium, sulfate, calcium, potassium , etc. In addition, sea spray aerosols may contain organic compounds, which influence their chemistry.

Secondary particles derive from the oxidation of primary gases such as sulfur and nitrogen oxides into sulfuric acid(liquid) and nitric acid (gaseous). The precursors for these aerosols i.e. the gases from which they originate may have an anthropogenic origin (from fossil fuel or coal combustion) and a natural biogenic origin. In the presence of ammonia, secondary aerosols often take the form of ammonium salts; i.e. ammonium sulfate and ammonium nitrate(both can be dry or in aqueous solution); in the absence of ammonia, secondary compounds take an acidic form as sulfuric acid (liquid aerosol droplets) and nitric acid (atmospheric gas), all of which may contribute to the health effects of particulates
Secondary sulfate and nitrate aerosols are strong light-scatterers. This is mainly because the presence of sulfate and nitrate causes the aerosols to increase to a size that scatters light effectively.

Organic matter $(\mathrm{OM})$ can be either primary or secondary, the latter part deriving from the oxidation of VOCs; organic material in the atmosphere may either be biogenic or anthropogenic. Organic matter influences the atmospheric radiation field by both scattering and absorption. Another important aerosol type is elemental carbon (EC, also known as black carbon, $\mathrm{BC})$ : this aerosol type includes strongly light-absorbing material and is thought to yield large positive radiative forcing. Organic matter and elemental carbon together constitute the carbonaceous fraction of aerosols. Secondary organic aerosols, tiny "tar balls" resulting from combustion products of internal combustion engines, have been identified as a danger to health. The chemical composition of the aerosol directly affects how it interacts with solar radiation. The chemical constituents within the aerosol change the overall refractive index. The refractive index will determine how much light is scattered and absorbed.

The composition of particulate matter that generally causes visual effects such as smog consists of sulfur dioxide, nitrogen oxides, carbon monoxide, mineral dust, organic matter, and elemental carbon also known as black carbon or soot. The particles are hydroscopic due to the presence of sulfur, and $\mathrm{SO}_{2}$ is converted to sulfate when high humidity and low temperatures are present. This causes the reduced visibility and yellow color

\section{Size distribution of Particles}

Aerosol particles of natural origin (such as windblown dust) tend to have a larger radius than human-produced aerosols such as particle pollution. The false-color maps in the third image on this page show where there are natural aerosols, human pollution, or a mixture of both, monthly.

Among the most obvious patterns that the size 
distribution time series shows is that in the planet's most southerly latitudes, nearly all the aerosols are large, but in the high northern latitudes, smaller aerosols are very abundant. Most of the Southern Hemisphere is covered by ocean, where the largest source of aerosols is natural sea salt from dried sea spray. Because land is concentrated in the Northern Hemisphere, the amount of small aerosols from fires and human activities is greater there than in the Southern Hemisphere. Over land, patches of large-radius aerosols appear over deserts and arid regions, most prominently, the Sahara Desert in north Africa and the Arabian Peninsula, where dust storms are common. Places where human-triggered or natural fire activity is common (land-clearing fires in the Amazon from August-October, for example, or lightning-triggered fires in the forests of northern Canada in Northern Hemisphere summer) are dominated by smaller aerosols. Human-produced (fossil fuel) pollution is largely responsible for the areas of small aerosols over developed areas such as the eastern United States and Europe, especially in their summer. Satellite measurements of aerosols, called aerosol optical thickness, are based on the fact that the particles change the way the atmosphere reflects and absorbs visible and infrared light. As shown in the seventh image on this page, an optical thickness of less than 0.1 (palest yellow) indicates a crystal clear sky with maximum visibility, whereas a value of 1 (reddish brown) indicates very hazy conditions

\section{Health problems}

The effects of inhaling particulate matter that have been widely studied in humans and animals include asthma, lung cancer, cardiovascular disease, respiratory diseases, premature delivery, birth defects, and premature death.

Increased levels of fine particles in the air as a result of anthropogenic particulate air pollution "is consistently and independently related to the most serious effects, including lung cancerl and other cardiopulmonarymortality The large number of deathsand other health problems associated with particulate pollution was first demonstrated in the early 1970s and has been reproduced many times since. PM pollution is estimated to cause 22,000-52,000 deaths per year in the United States (from 2000) ontributed to $\sim 370,000$ premature deaths in Europe during 2005. and 3.22 million deaths globally in 2010 per theglobal burden of disease collaboration. A 2002 study indicated that $\mathrm{PM}_{2.5}$ leads to high plaque deposits in arteries, causing vascular inflammation andatherosclerosis a hardening of the arteries that reduces elasticity, which can lead to heart attacks and other cardiovascular problems. A 2014 meta analysis reported that long term exposure to particulate matter is linked to coronary events. The study included 11 cohorts participating in the European Study of Cohorts for Air Pollution Effects (ESCAPE) with 100,166 participants, followed for an average of 11.5 years. An increase in estimated annual exposure to PM 2.5 of just $5 \mu \mathrm{g} / \mathrm{m}^{3}$ was linked with a 13\% increased risk of heart attacks.The World Health Organization (WHO) estimated in 2005 that fine particulate air pollution $(\mathrm{PM}(2.5))$, causes about $3 \%$ of mortality from cardiopulmonary disease, about $5 \%$ of mortality from cancer of the trachea, bronchus, and lung, and about $1 \%$ of mortality from acute respiratory infections in children under 5 years, worldwide.". Short-term exposure at elevated concentrations can significantly contribute to heart disease. A 2011 study concluded that traffic exhaust is the single most serious preventable cause of heart attack in the general public, the cause of $7.4 \%$ of all attacks. The largest US study on acute health effects of coarse particle pollution between 2.5 and 10 micrometers in diameter was published 2008 and found an association with hospital admissions for cardiovascular diseases but no evidence of an association with the number of hospital admissions for respiratory diseases. After taking into account fine particle levels (PM 2.5 and less), the association with coarse particles remained but was no longer statistically significant, which means the effect is due to the subsection of fine particles.

Particulate matter studies in Bangkok Thailand from 2008 indicated a 1.9\% increased risk of dying from cardiovascular disease, and $1.0 \%$ risk of all disease for every 10 micrograms per cubic meter. Levels averaged 65 in 1996, 68 in 2002, and 52 in 2004. Decreasing levels may be attributed to conversions of diesel to natural gas combustion as well as improved regulations. The Mongolian government agency recorded a $45 \%$ increase in the rate of respiratory illness in the past five years (reported in September, 2014). Bronchial asthma, chronic obstructive pulmonary disease and interstitial pneumonia were the most common ailments treated by area hospitals. Levels of premature death, chronic bronchitis, and cardiovascular disease are increasing at a rapid rate. It has been suggested that particulate matter can cause similar brain damage as that found in Alzheimerpatients

\section{Effects on Vegetation}

Particulate matter can clog stomatal openings of plants and interfere with photosynthesis functions.[59] In this manner high particulate matter concentrations in the atmosphere can lead to growth stunting or mortality in some plant species.

\section{Effects on Health}

Since particulate matter is found in the form of aerosols, its impact on human health, through inhalation, has been noted in epidemiological findings. Particularly dangerous are fine (PM2.5) and ultra-fine (PM1) particles which, when inhaled, can travel deep into the human bronchi and lungs which causes various health issues including chronic lung tissue In most urban areas, transportation is one of the most significant sources of suspended 
particulate matter, which has led to concerns about those living close to big and active roads. Locations where emissions from specific sources may expose individuals and population groups to elevated risks of adverse health effects are known as hot

Spots For example, people living in street canyons, which are areas where the source of pollution (usually a big road) is flanked (most commonly by buildings) in such a way that traps pollution are especially vulnerable to the effects of traffic-caused PM pollution. While there are no street canyons to speak of in Iceland, they exist in most big cities elsewhere and they have been a source of much research. In fact, the effect on health of transport-related air pollution is one of the leading concerns about transport and the need for its regulation with regards to air quality. Several studies show higher rates of respiratory symptoms and reduced lung capacity in people living close to major roadways (Another target of research are groups of people that are particularly vulnerable to airborne pollutants, such as children, the elderly, people suffering from asthma and similar respiratory issues, as well as certain occupational groups, such as professional drivers and railway have reviewed various research on health effects of transportrelated air pollution and their research indicates that transport-related air pollution contributes to an increased risk of death, mainly from cardiopulmonary causes. In addition, it increases the risk of pulmonary symptoms and diseases. According to a few studies, there is a significant increase in the risk of myocardial infarction after exposure to air pollution. Some studies also point to an increased risk of lung cancer in people with long term exposure to transport-related air pollution, mainly through their occupation some chronic respiratory tract inflammation, caused by PM presence in the lung tissue (mainly bacterial lipopolysaccharide and combustion-derived metals), to chronic inflammations of the brain. Their research has shown that the pathology of people chronically exposed to air pollution has a number of similarities to the pathology of people afflicted by Alzheimer's disease. Particulate matter has been linked to allergic responses and fine PM is associated with increased risk of mortality and respiratory morbidity It is also known that ambient air pollution can have adverse effects on pregnancy, including an increase in post neo-natal infant mortality foetuses are considered to be more vulnerable to environmental effects due to higher rates.

\section{Effects of Vegetation on Particulate Matter}

Effects of vegetation on mitigating air pollution have become increasingly interesting for researchers as well as urban planners since trees, besides being known for their carbon sequestration, are noted to be effective in removing pollutants, especially particulate matter (e.g. PM10), nitrogen dioxide (NO2), sulphur dioxide (SO2) and ozone (O3), from the air Research shows that due to overall greater leaf surface and more turbulent mixing of air in their vicinity, trees are more efficient in capturing pollutants than shorter vegetation .woodland is around 3 times more effective in capturing particles than grassland. Thisindicates that increasing the tree cover in urban areas helps mitigate traffic-related airpollution through dry deposition.

\section{Regulations}

Due to the highly toxic health effects of particulate matter, most governments have created regulations both for the emissions allowed from certain types of pollution sources (motor vehicles, industrial emissions etc.) and for the ambient concentration of particulates. The IARC and WHO designates particulates a Group 1 carcinogen. Particulates are the deadliest form of air pollution due to their ability to penetrate deep into the lungs and blood streams unfiltered, causing permanent DNA mutations, heart

attacks and premature death. In 2013, the ESCAPE study involving 312,944 people in nine European countries revealed that there was no safe level of particulates, and that for every increase of $10 \mu \mathrm{g} / \mathrm{m} 3$ in PM10, the lung cancer rate rose $22 \%$. For PM2.5 there was a $36 \%$ increase in lung cancer per $10 \mathrm{\mu g} / \mathrm{m} 3$. In a 2014 metaanalysis of 18 studies globally including the ESCAPE data, for every increase of $10 \mu \mathrm{g} / \mathrm{m} 3$ in PM2.5, the lung cancer rate rose $9 \%$

\section{References:}

1) Beckett, K. P., Freer-Smith, P. H., \& Taylor, G. (2000b). The capture of particulate pollution by trees at five contrasting UK urban sites. Arboricultural Journal

2) Donaldson, K., Stone, V., Clouter, A., Renwick, L., \& MacNee, W. (2001). Ultrafine particles. Occup Environ Med, 58: 211-216.

3) Dominick Dal Santo. "The Encyclopedia of Dust Collection".

4) Hogan, C.Michael (2010). Emily Monosson and C. Cleveland, ed. "Abiotic factor". Encyclopedia of Earth. National Council for Science and the Environment

5.) Aaron J. Cohen, H. Ross Anderson, Bart Ostro; Ross Anderson, H; Ostro, B; Pandey, K. D.; Krzyzanowski, M; Künzli, N; Gutschmidt, K; Pope, A; Romieu, I; Samet, J. M.; Smith, K (2005). "The Global Burden of Disease Due to Outdoor Air Pollution". 